\title{
Novel deadbeat predictive control strategy for DFIG's back to back power converter
}

\author{
Manale Bouderbala ${ }^{1}$, Badre Bossoufi ${ }^{1}$, Hala Alami Aroussi ${ }^{2}$, Mohammed Taoussi ${ }^{1}$, Ahmed Lagrioui ${ }^{3}$ \\ ${ }^{1}$ Faculty of Sciences Dhar El Mahraz, Sidi Mohammed Ben Abdellah University, Fez, Morocco \\ ${ }^{2}$ Ecole Supérieur de Technologie, Mohamed Premier University, Oudja, Morocco \\ ${ }^{3}$ The Higher National School of Arts and Trades, Moulay Ismail University, Meknes, Morocco
}

\begin{tabular}{l} 
Article Info \\
\hline Article history: \\
Received Aug 29, 2021 \\
Revised Jan 17, 2022 \\
Accepted Jan 24, 2022 \\
\hline Keywords: \\
Deadbeat \\
Doubly fed induction generator \\
(DFIG) \\
Predictive control \\
Wind energy conversion \\
systems (WECS)
\end{tabular}

\begin{abstract}
To successfully carry out a wind energy conversion system, it is necessary to simultaneously control the rotor and the grid side. This paper proposes a doubly-fed induction generator's predictive power control. While the powers are controlled indirectly through currents, the latter is controlled using the deadbeat command. Based on discrete-time, the control suggests at each sample period the required voltages to the the-back-to-back converter to reach the desired setpoints, control the powers, and the DC link voltages. For these reasons, a presentation of the system is given first, then a description of the predictive control, followed by applying this strategy on the rotor side control and grid side control. Finally, a random wind profile was applied to analyze the system's performance with a unitary power factor. The simulation results are presented in the MATLAB/Simulink environment using a $1.5 \mathrm{~kW}$ DFIG. The results obtained by applying a random wind profile have well fulfilled the objectives of the control and the system robustness is approved by the excellent tracking allowing the machine's internal parameters variation. By comparing the quality and the tracking reference of the proposed control method to other control methods, the deadbeat controller was very promising.
\end{abstract}

This is an open access article under the CC BY-SA license.

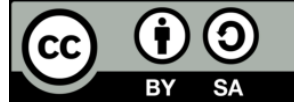

\section{Corresponding Author:}

Manale Bouderbala

Faculty of Sciences Dhar El Mahraz, Sidi Mohammed Ben Abdellah University Fez

B.P. 1796 Fès-Atlas 30003, Morocco

Email: manale.bouderbala@usmba.ac.ma

\section{INTRODUCTION}

The energy transition is defined as the subtraction of fossil energy to clean energy. To limit the climate change effect, greenhouse gas $(\mathrm{GHG})$ emissions need to be reduced in the energy production sector [1]. According to the international renewable energy agency (IRENA), the promoter's actions and measures of renewable energy and energy efficiency could reach $90 \%$ of the required carbon reductions by 2050 . For that purpose, control information and smart technologies need to be more developed [2].

To deal with this situation, Morocco has adopted an ambitious national strategy to reduce GHG emissions and secure its electricity supply through the large-scale development of renewable energies and energy efficiency. For that purpose, significant reform of the legislative and regulatory framework has been initiated. This profound change in the energy sector towards renewable energy must be accompanied by a change in the practices and technologies of generation, transport, and energy use.

In fact, Morocco had $3000 \mathrm{MW}$ installed renewable energy (RE) capacity (1770 MW of hydro, 1015 MW of wind, and $180 \mathrm{MW}$ of solar) according to the Moroccan agency for renewable energies (MASEN) in 2017. Today, Morocco faces a new challenge: the Kingdom has decided to increase clean energy in the 
electricity mix from $33 \%$ in 2017 to $42 \%$ by 2021 [2]. Within this framework, the Moroccan program for the development of wind energy falls within the framework of public/private partnerships or private projects of new wind farms, which will bring the installed electrical power of wind power to $2000 \mathrm{MW}$ by the end of 2021.

In this context, this work aims to elaborate an optimal design of a wind power system. By looking at the literature, Kumar \& al. proposed a review of the different wind turbine technologies and three kinds of wind systems were presented: Permanent magnet synchronous generator (PMSG), squirrel cage induction machine (SCIG), and doubly fed induction generator (DFIG) [3]. The most common promoters of the wind turbine industry, such as siemens Gamesa, Suzlon, and Enercon, commonly use DFIG with installed powers ranging from $1.5 \mathrm{MW}$ to $6 \mathrm{MW}$ to produce wind energy conversion systems (WECS). DFIG has the most significant average power capacity [4], thanks to its ability to generate power from both stator and rotor. This advantage came from its capacity to operate into two modes: sub synchronism and hyper synchronism, depending on wind speed [5] .

For practical, stable, and optimal energy production, active and reactive powers, currents, and voltages need to be controlled. Among the control strategies, vector control is used widely. To simplify the control, field-oriented control (FOC) was used to make DFIG similar to direct current (DC) via the proportional integrator (PI) regulator. Therefore, PI controllers have some drawbacks, such its limited performance under external disturbance [6]. To deal with this issue, other alternatives have been proposed. In [7] authors proposed adaptative backstepping control as an alternative to FOC. This control uses the Lyapunov function to ensure better system stability [8], [9]. Nevertheless, on the other hand, determining the Lyapunov function is complicated because it relies on experience and luck. Arrousi et al. [10], the authors suggested a detailed direct power control (DPC) study based on hysteresis comparators. DPC's main advantage is its independence from system parameters, and decoupling between system variables is no longer needed [11]. In [12] authors suggested sliding mode control. This technique deals very well with uncertainties and parameter variations to make the system more robust [13]. However, this latter is the origin of chattering phenomena [14].

On the other hand, predictive control is an effective control strategy for machines and converters as an alternative to FOC [15]. It is based on the system model, which can predict the behavior of controlled variables. It suggests an optimal control for each sampling interval. It is exceptionally efficient since it can manage the constraints, system states, and output variables [16]. However, some researchers in predictive control focused either on the rotor side control (RSC) [17] or the grid side control (GSC) aside [18]. Although to successfully carry out the system, it is necessary to control rotor and Grid Side simultaneously. In the interest of filling this gap, the deadbeat predictive controller is applied to control the RSC and the GSC of the DFIG. The main purpose of this control is to ensure a maximum of active power (tracking the shape of wind) with a unit power factor sinusoidal currents and voltages; with a normalized frequency and a low total harmonic distortion (THD) to be able to inject the produced electricity into the grid. This aim is supposed to be fully filed by ensuring the closest measured variables to the predictive ones that need to be applied to the back to back converters.

In order to apply the necessary voltages, rotor currents need to be controlled through the predictive regulator. The rotor side converter provides the voltages required to control the power exchanged between the stator and the grid. The grid side converter controls the bi-directional power exchange between the grid and the rotor by adjusting the Dc link and grid currents.

This paper aims to develop the predictive current control method for WECS. This method provides reference tracking of current and carries out power tracking by eliminating errors in each sampling period. It provides a faster dynamic response like conventional model predictive control methods. Besides, evaluating the switching state or voltage level, calculating the cost function, and selecting the weighting factor is not required. The developed control is designed to ensure optimal operation and improve the quality of energy produced by WECS through the combination of control between RSC and GSC and acting on the system performance and response time.

The introduction is presented in the first section of this article. The mathematical modelling of the wind energy conversion system is discussed in section 2. Section 3 introduces the deadbeat method and provides a detailed mathematical demonstration of the proposed control applied to RSC and GSC. The simulations results are presented and discussed in section 5; a performance's comparison is also provided with previous works. Finally, a conclusion is given in the last section.

\section{MATHEMATICAL MODELLING OF THE SYSTEM}

The WECS system is composed of a turbine linked to DFIG via a gearbox to adjust the speed. The stator is connected directly to the grid. Therefore, the rotor is linked to the grid by the back-to-back 
converters. This latter has the task of applying the control to the system. WECS system consists of producing electrical energy from the wind. The power of the wind $(\mathrm{Pv})$ produced by a turbine depends on three parameters: air density $(\rho)$, wind speed $(\mathrm{V})$, and the area swept by the blades. The power recoverable by a wind turbine is proportional to the surface swept by its rotor (S) and the cube of the wind speed [19], [20].

$$
\mathrm{P}_{\mathrm{v}}=\frac{\rho \cdot S \cdot \mathrm{V}^{3}}{2}
$$

The DFIG stator is linked directly to the grid, while its rotor is linked via a back-to-back converter. Based on the DFIG space vector model, the mathematical model of the DFIG is expressed in the (d-q) reference frame as follows [21], [22]. Where, R, L refers respectively to Resistance and Inductance (machine's parameter). The indicators $\mathrm{s}$ and $\mathrm{r}$ refer to stator and rotor. The voltages in the referential $(\mathrm{d}, \mathrm{q})$ :

$$
\begin{aligned}
& \mathrm{V}_{\mathrm{sd}}=\mathrm{R}_{\mathrm{s}} \cdot \mathrm{I}_{\mathrm{sd}}+\frac{\mathrm{d} \varphi_{\mathrm{sd}}}{\mathrm{dt}}-\varphi_{\mathrm{sq}} \cdot \omega_{\mathrm{s}} \\
& \mathrm{V}_{\mathrm{sq}}=\mathrm{R}_{\mathrm{s}} \cdot \mathrm{I}_{\mathrm{sq}}+\frac{\mathrm{d} \varphi_{\mathrm{sq}}}{\mathrm{dt}}+\varphi_{\mathrm{sd}} \cdot \omega_{\mathrm{s}} \\
& \mathrm{V}_{\mathrm{rd}}=\mathrm{R}_{\mathrm{r}} \cdot \mathrm{I}_{\mathrm{rd}}+\frac{\mathrm{d} \varphi_{\mathrm{rd}}}{\mathrm{dt}}-\varphi_{\mathrm{rq}} \cdot \omega_{\mathrm{r}} \\
& \mathrm{V}_{\mathrm{rq}}=\mathrm{R}_{\mathrm{r}} \cdot \mathrm{I}_{\mathrm{rq}}+\frac{\mathrm{d} \varphi_{\mathrm{rq}}}{\mathrm{dt}}+\varphi_{\mathrm{rd}} \cdot \omega_{\mathrm{r}}
\end{aligned}
$$

The fluxes in the referential $(\mathrm{d}, \mathrm{q})$ :

$$
\begin{aligned}
& \varphi_{\mathrm{sd}}=\mathrm{L}_{\mathrm{s}} \cdot \mathrm{I}_{\mathrm{sd}}+\mathrm{L}_{\mathrm{M}} \cdot \mathrm{I}_{\mathrm{rd}} \\
& \Phi_{\mathrm{sq}}=\mathrm{L}_{\mathrm{s}} \cdot \mathrm{I}_{\mathrm{sq}}+\mathrm{L}_{\mathrm{M}} \cdot \mathrm{I}_{\mathrm{rq}} \\
& \varphi_{\mathrm{rd}}=\mathrm{L}_{\mathrm{r}} \cdot \mathrm{I}_{\mathrm{rd}}+\mathrm{L}_{\mathrm{M}} \cdot \mathrm{I}_{\mathrm{sd}} \\
& \varphi_{\mathrm{rq}}=\mathrm{L}_{\mathrm{r}} \cdot \mathrm{I}_{\mathrm{rq}}+\mathrm{L}_{\mathrm{M}} \cdot \mathrm{I}_{\mathrm{sq}}
\end{aligned}
$$

The active and reactive powers:

$$
\begin{aligned}
& \mathrm{P}_{s}=\mathrm{V}_{\mathrm{sd}} \cdot \mathrm{I}_{\mathrm{sd}}+\mathrm{V}_{\mathrm{sq}} \cdot \mathrm{I}_{\mathrm{sq}} \\
& \mathrm{Q}_{\mathrm{s}}=\mathrm{V}_{\mathrm{sq}} \cdot \mathrm{I}_{\mathrm{sd}}-\mathrm{V}_{\mathrm{sd}} \cdot \mathrm{I}_{\mathrm{sq}} \\
& \mathrm{P}_{r}=\mathrm{V}_{\mathrm{rd}} \cdot \mathrm{I}_{\mathrm{rd}}+\mathrm{V}_{\mathrm{rq}} \cdot \mathrm{I}_{\mathrm{rq}} \\
& \mathrm{Q}_{\mathrm{r}}=\mathrm{V}_{\mathrm{rq}} \cdot \mathrm{I}_{\mathrm{rd}}-\mathrm{V}_{\mathrm{rd}} \cdot \mathrm{I}_{\mathrm{rq}}
\end{aligned}
$$

The power converter is an essential component for controlling the WECS. It is composed of two converters (AC/DC/AC) linked by a DC bus. Its function is to regulate the DFIG's powers and currents, then provide the optimal active power and unit power factor to the grid [23], [24], [25].

\section{DEADBEAT STRATEGY}

For a specific control variable, predictive control uses the system model to anticipate future process behavior then achieve optimal action based on predefined optimization criteria. This strategy identifies the appropriate control variables that cancel the error between the control variable and the reference input [18]. In general, the continuous representation of a system is presented as [26], [27]:

$$
\left\{\begin{array}{c}
\dot{\bar{x}} \dot{(t)}=A \bar{x}(t)+B \bar{u}(t)+G \bar{w}(t) \\
\bar{y}(t)=C \bar{x}(t)
\end{array}\right.
$$

$\mathrm{x}(\mathrm{t})$ represents the stator vector to be controlled (e.g. voltage, flux, speed, current, torque, power...) $\mathrm{u}(\mathrm{t}), \mathrm{y}(\mathrm{t})$ represents input and output vectors, respectively (e.g. voltage, current, torque.) 
$\mathrm{w}(\mathrm{t})$ perturbation

$\mathrm{A}, \mathrm{B}, \mathrm{G}$ are $\mathrm{n} * \mathrm{n}$ matrices and $\mathrm{C}$ Identity matrix

The representation of the system in the discrete-time is necessary to know the behavior of the system. It is written as [28]:

$$
\overline{\mathrm{x}}_{\mathrm{k}+1}=\widetilde{\mathrm{A}} \overline{\mathrm{x}}(\mathrm{k})+\widetilde{\mathrm{B}} \overline{\mathrm{u}}(\mathrm{k})+\widetilde{\mathrm{G}} \overline{\mathrm{w}}(\mathrm{k})
$$

This discretization is obtained by making the following transformation:

$$
\widetilde{\mathrm{A}}=\mathrm{e}^{\mathrm{AT}}=\mathrm{I}+\mathrm{AT}, \widetilde{\mathrm{B}}=\int_{0}^{\mathrm{T}} \mathrm{e}^{\mathrm{AT}} \mathrm{B} \mathrm{d} \tau=\mathrm{BT}, \widetilde{\mathrm{G}}=\int_{0}^{\mathrm{T}} \mathrm{e}^{\mathrm{AT}} \mathrm{G} \mathrm{d} \tau=\mathrm{GT}
$$

To obtain the deadbeat control, the reference is set equal to the next sampling instant:

$$
\overline{\mathrm{x}}_{\mathrm{k}+1}=\mathrm{x}_{\mathrm{ref}}
$$

The (18) is obtained by injecting (17) in (15):

$$
\overline{\mathrm{u}}(\mathrm{k})=\widetilde{\mathrm{B}}^{-1} \cdot \overline{\mathrm{x}}_{\mathrm{ref}}-\widetilde{\mathrm{A}} \cdot \widetilde{\mathrm{B}}^{-1} \cdot \overline{\mathrm{x}}(\mathrm{k})-\widetilde{\mathrm{B}}^{-1} \cdot \widetilde{\mathrm{G}} \cdot \overline{\mathrm{w}}_{\mathrm{d}}(\mathrm{k})
$$

The deadbeat control method operates under a high proportional controller gain. On the other hand, resulted power must track the reference by ensuring a steady-state null error. The input corrector can be written as (19):

$$
\overline{\mathrm{u}}(\mathrm{k})=\mathrm{F}\left(\overline{\mathrm{x}}_{\mathrm{k}+1}-\overline{\mathrm{x}}\right)
$$

Where $\mathrm{F}$ is the gain matrix.

The requisite input is determined using the following formula:

$$
\overline{\mathrm{u}}(\mathrm{k})=\widetilde{\mathrm{B}}^{-1} \cdot \widetilde{\mathrm{A}}^{-1}\left[\widetilde{\mathrm{A}}^{-1} \cdot \overline{\mathrm{x}}_{\mathrm{ref}}-\overline{\mathrm{x}}(\mathrm{k})\right]-\widetilde{\mathrm{B}}^{-1} \cdot \widetilde{\mathrm{G}} \cdot \overline{\mathrm{w}}_{\mathrm{d}}(\mathrm{k})
$$

\subsection{Rotor side control}

By adjusting the rotor currents (Ird and Irq) through the predictive regulator, the rotor side converter (RSC) provides the voltages required (Vr) to control both Ps and Qs [29]. Vector control is applied to ensure decoupling between direct and quadrature components [30]. Therefore, the stator flux vector is aligned with the $\mathrm{d}$ axe. As results, the flux and voltage equations become:

$$
\begin{aligned}
& \varphi_{\mathrm{sq}}=0, \varphi_{\mathrm{sd}}=\varphi_{\mathrm{s}} \\
& \mathrm{V}_{\mathrm{sd}}=0, \mathrm{~V}_{\mathrm{sq}}=\varphi_{\mathrm{sd}} \cdot \omega_{\mathrm{s}}
\end{aligned}
$$

In (23) and (24) are obtained by injecting (8) and (9) into (4) and (5) respectively.

$$
\begin{aligned}
& V_{r d}=R_{r} \cdot I_{r d}-L_{r} \cdot \omega_{r} \cdot I_{r q}+\sigma \cdot \frac{d I_{r d}}{d t}-L_{M} \cdot \omega_{r} \cdot I_{s q} \\
& V_{r q}=R_{r} \cdot I_{r q}-L_{r} \cdot \omega_{r} \cdot I_{r d}+\sigma \cdot \frac{d I_{r q}}{d t}+L_{M} \cdot \omega_{r} \cdot I_{s d}
\end{aligned}
$$

Using the previous equation, a state-space representation is given by the:

$$
\left[\begin{array}{c}
\frac{\mathrm{dI}_{\mathrm{rd}}}{\mathrm{dt}} \\
\frac{\mathrm{dI}_{\mathrm{rq}}}{\mathrm{dt}}
\end{array}\right]=\left[\begin{array}{cc}
\frac{-\mathrm{R}_{\mathrm{r}}}{\sigma \cdot \mathrm{Lr}_{\mathrm{r}}} & \frac{\omega_{\mathrm{r}}}{\sigma} \\
\frac{-\omega_{\mathrm{r}}}{\sigma} & \frac{-\mathrm{R}_{\mathrm{r}}}{\sigma . \mathrm{Lr}}
\end{array}\right] *\left[\begin{array}{c}
\mathrm{I}_{\mathrm{rd}} \\
\mathrm{I}_{\mathrm{rq}}
\end{array}\right]+\left[\begin{array}{cc}
\frac{1}{\sigma \cdot \mathrm{L}_{\mathrm{r}}} & 0 \\
0 & \frac{1}{\sigma \cdot \mathrm{L}_{\mathrm{r}}}
\end{array}\right] *\left[\begin{array}{c}
\mathrm{V}_{\mathrm{rd}} \\
\mathrm{V}_{\mathrm{rq}}
\end{array}\right]+\left[\begin{array}{cc}
0 & \frac{\omega_{\mathrm{r}} \cdot \mathrm{L}_{\mathrm{M}}}{\sigma \cdot \mathrm{L}_{\mathrm{r}}} \\
\frac{-\omega_{\mathrm{r}} \cdot \mathrm{L}_{\mathrm{M}}}{\sigma \cdot \mathrm{L}_{\mathrm{r}}} & 0
\end{array}\right] *\left[\begin{array}{c}
\mathrm{I}_{\mathrm{sd}} \\
\mathrm{I}_{\mathrm{sq}}
\end{array}\right]
$$

with: $\sigma=1-\frac{\mathrm{L}_{\mathrm{M}}{ }^{2}}{\mathrm{~L}_{\mathrm{S}} \cdot \mathrm{L}_{\mathrm{r}}}$

By applying (14) on the system parameters, the rotor currents can be discretized as: 


$$
\widetilde{\mathrm{A}}_{\mathrm{r}}=\left[\begin{array}{cc}
1-\frac{\mathrm{R}_{r} \cdot \mathrm{T}}{\sigma \cdot \mathrm{L}_{r}} & \frac{\omega_{\mathrm{r}} \cdot \mathrm{T}}{\sigma} \\
\frac{-\omega_{r} \cdot \mathrm{T}}{\sigma} & 1-\frac{\mathrm{R}_{r} \cdot \mathrm{T}}{\sigma \cdot \mathrm{L}_{r}}
\end{array}\right] \widetilde{\mathrm{B}}_{\mathrm{r}}=\left[\begin{array}{cc}
\frac{\mathrm{T}}{\sigma \cdot \mathrm{L}_{\mathrm{r}}} & 0 \\
0 & \frac{\mathrm{T}}{\sigma \cdot \mathrm{L}_{\mathrm{r}}}
\end{array}\right] \widetilde{\mathrm{G}}_{\mathrm{r}}=\left[\begin{array}{cc}
0 & \frac{\omega_{\mathrm{r}} \cdot \mathrm{L}_{\mathrm{M}} \cdot \mathrm{T}}{\sigma \cdot \mathrm{L}_{\mathrm{r}}} \\
\frac{-\omega_{\mathrm{r}} \mathrm{L}_{\mathrm{M}} \cdot \mathrm{T}}{\sigma \cdot \mathrm{L}_{\mathrm{r}}} & 0
\end{array}\right]
$$

The resulting rotor voltages equations can be expressed as:

$$
\begin{aligned}
& \mathrm{V}_{\mathrm{rd}}(\mathrm{k})=\frac{\sigma \cdot \mathrm{L}_{\mathrm{r}}}{\mathrm{T}}\left(\mathrm{I}_{\mathrm{rd}}(\mathrm{k}+1)-\mathrm{I}_{\mathrm{rd}}(\mathrm{k})\right)+\mathrm{R}_{\mathrm{r}} \cdot \mathrm{I}_{\mathrm{rd}}(\mathrm{k})-\mathrm{L}_{\mathrm{r}} \cdot \omega_{\mathrm{r}} \cdot \mathrm{I}_{\mathrm{rq}}(\mathrm{k})-\mathrm{L}_{\mathrm{M}} \cdot \omega_{\mathrm{r}} \cdot \mathrm{I}_{\mathrm{sq}}(\mathrm{k}) \\
& \mathrm{V}_{\mathrm{rq}}(\mathrm{k})=\frac{\sigma \cdot \mathrm{L}_{\mathrm{r}}}{\mathrm{T}}\left(\mathrm{I}_{\mathrm{rq}}(\mathrm{k}+1)-\mathrm{I}_{\mathrm{rq}}(\mathrm{k})\right)+\mathrm{R}_{\mathrm{r}} \cdot \mathrm{I}_{\mathrm{rq}}(\mathrm{k})+\mathrm{L}_{\mathrm{r}} \cdot \omega_{\mathrm{r}} \cdot \mathrm{I}_{\mathrm{rd}}(\mathrm{k})+\mathrm{L}_{\mathrm{M}} \cdot \omega_{\mathrm{r}} \cdot \mathrm{I}_{\mathrm{sd}}(\mathrm{k})
\end{aligned}
$$

It can be seen from (27) and (28) that this control method handles the machine variables, including the stator currents.

$$
\begin{aligned}
& \mathrm{P}_{\mathrm{s}}=-\frac{3}{2} \cdot \frac{\mathrm{L}_{\mathrm{M}}}{\varphi_{\mathrm{sd}}} \cdot \mathrm{V}_{\mathrm{s}} \cdot \mathrm{I}_{\mathrm{rq}} \\
& \mathrm{Q}_{\mathrm{s}}=-\frac{3}{2} \cdot \mathrm{V}_{\mathrm{s}}\left(\frac{\varphi_{\mathrm{sd}}}{\mathrm{L}_{\mathrm{s}}}-\frac{\mathrm{L}_{\mathrm{M}}}{\mathrm{L}_{\mathrm{s}}} \cdot \mathrm{I}_{\mathrm{rd}}\right)
\end{aligned}
$$

Considering the assumption of (17), the current references (Ird_ref and Irq_ref) are set equal to the currents at the next sampling time $\operatorname{Ird}(\mathrm{k}+1)$ and $\operatorname{Irq}(\mathrm{k}+1)$ respectively. The Irq_ref and Ird_ref are expressed as:

$$
\begin{aligned}
& I_{\text {rq_ref }}=-\frac{2}{3} \cdot \frac{P_{\text {ref }} \cdot L_{s}}{V_{s} \cdot L_{M}} \\
& I_{\text {rd_ref }}=-\frac{2}{3} \cdot \frac{Q_{\text {ref }} \cdot L_{s}}{V_{s} \cdot L_{M}}+\frac{\varphi_{s}}{L_{M}}
\end{aligned}
$$

\subsection{Grid side control}

By controlling the grid currents Igd and Igq through the predictive regulator, the grid side converter (GSC) provides the voltages required (Vf) allowing the control of the active power bi-directionally exchanged between the rotor and the grid. The power factor and the DC bus voltage are controlled as well. By orienting the grid voltage $(\mathrm{Vg})$ along the $\mathrm{q}$ axis, $\mathrm{Vgd}$ is set equal to zero $\mathrm{Vgd}=0 \& \mathrm{Vgq}=\mathrm{Vg}$. The voltages exchanged between the Grid supply and Grid side converter in the continuous dq frame become:

$$
\begin{aligned}
& V_{f d}=R_{f} \cdot I_{g d}+L_{f} \cdot \frac{d I_{g d}}{d t}-L_{f} \cdot \omega_{s} \cdot I_{g q} \\
& V_{f q}=V_{g q}+R_{f} \cdot I_{g q}+L_{f} \cdot \frac{d I_{g q}}{d t}+L_{f} \cdot \omega_{s} \cdot I_{g d}
\end{aligned}
$$

Using the previous equation, state-space representation is given by the:

$$
\left[\begin{array}{c}
\frac{\mathrm{dI}_{\mathrm{gd}}}{\mathrm{dt}} \\
\frac{\mathrm{dI} \mathrm{gq}}{\mathrm{dt}}
\end{array}\right]=\left[\begin{array}{cc}
\frac{-\mathrm{R}_{\mathrm{f}}}{\mathrm{L}_{\mathrm{f}}} & \omega_{\mathrm{s}} \\
\omega_{\mathrm{s}} & \frac{-\mathrm{R}_{\mathrm{f}}}{\mathrm{L}_{\mathrm{f}}}
\end{array}\right] *\left[\begin{array}{l}
\mathrm{I}_{\mathrm{gd}} \\
\mathrm{I}_{\mathrm{gq}}
\end{array}\right]+\frac{1}{\mathrm{~L}_{\mathrm{f}}} *\left[\begin{array}{c}
\mathrm{V}_{\mathrm{fd}} \\
\mathrm{V}_{\mathrm{fq}}
\end{array}\right]+\left[\begin{array}{cc}
0 & 0 \\
0 & \frac{-1}{\mathrm{~L}_{\mathrm{f}}}
\end{array}\right] *\left[\begin{array}{c}
\mathrm{V}_{\mathrm{gd}} \\
\mathrm{V}_{\mathrm{gq}}
\end{array}\right]
$$

By applying (14) on the system parameters, the filter current can be discretized as:

$$
\overline{\mathrm{I}}_{\mathrm{g}(\mathrm{d}, \mathrm{q})}(\mathrm{k}+1)=\widetilde{\mathrm{A}}_{\mathrm{g}} \cdot \overline{\mathrm{I}}_{\mathrm{g}(\mathrm{d}, \mathrm{q})}(\mathrm{k})+\widetilde{\mathrm{B}}_{\mathrm{g}} \cdot \overline{\mathrm{V}}_{\mathrm{f}(\mathrm{d}, \mathrm{q})}(\mathrm{k})+\widetilde{\mathrm{G}}_{\mathrm{g}} \cdot \overline{\mathrm{V}}_{\mathrm{g}(\mathrm{d}, \mathrm{q})}(\mathrm{k})
$$

The following discrete-time parameters are obtained by applying the required transformations given in (16)

$$
\widetilde{\mathrm{A}}_{\mathrm{g}}=\left[\begin{array}{cc}
1-\frac{\mathrm{R}_{f} \cdot \mathrm{T}}{\mathrm{L}_{f}} & -\omega_{s} \cdot \mathrm{T} \\
-\omega_{s} \cdot \mathrm{T} & 1-\frac{\mathrm{R}_{f} \cdot \mathrm{T}}{\mathrm{L}_{f}}
\end{array}\right] \widetilde{\mathrm{B}}_{\mathrm{g}}=\left[\begin{array}{cc}
\frac{\mathrm{T}}{\mathrm{L}_{\mathrm{f}}} & 0 \\
0 & \frac{\mathrm{T}}{\mathrm{L}_{\mathrm{f}}}
\end{array}\right] \widetilde{\mathrm{G}}_{\mathrm{g}}=\left[\begin{array}{cc}
0 & 0 \\
0 & \frac{-\mathrm{T}}{\mathrm{L}_{\mathrm{f}}}
\end{array}\right]
$$

The resulting voltages equations can be expressed as: 


$$
\begin{aligned}
& V_{f d}(k)=\frac{L_{f}}{T}\left(I_{g d}(k+1)-I_{g d}(k)\right)+R_{f} \cdot I_{g d}(k)-L_{f} \cdot \omega_{s} \cdot I_{g q}(k) \\
& V_{f q}(k)=\frac{L_{f}}{T}\left(I_{g q}(k+1)-I_{g q}(k)\right)+R_{f} \cdot I_{g q}(k)+L_{f} \cdot \omega_{s} \cdot I_{g d}(k)+V_{g q}(k)
\end{aligned}
$$

Considering the prediction variables $\operatorname{Igd}(\mathrm{k}+1)$ and $\operatorname{Igq}(\mathrm{k}+1)$ represent the grid reference currents Igd_ref and Igq_ref respectively. And based on the vectorial approach used and the grid power expressions, the reference grid currents are given by:

$$
\begin{aligned}
& I_{\text {gq_ref }}=\frac{P_{g_{\text {_ref }}}}{V_{\text {gq }}} \\
& I_{\text {gd_ref }}=\frac{Q_{\text {g_ref }}}{V_{\text {gq }}}
\end{aligned}
$$

The current Igd_ref is obtained directly from Qg_ref while the current Igq_ref is obtained by controlling the DC link voltage. Figure 1 shows the whole system with the control principle.

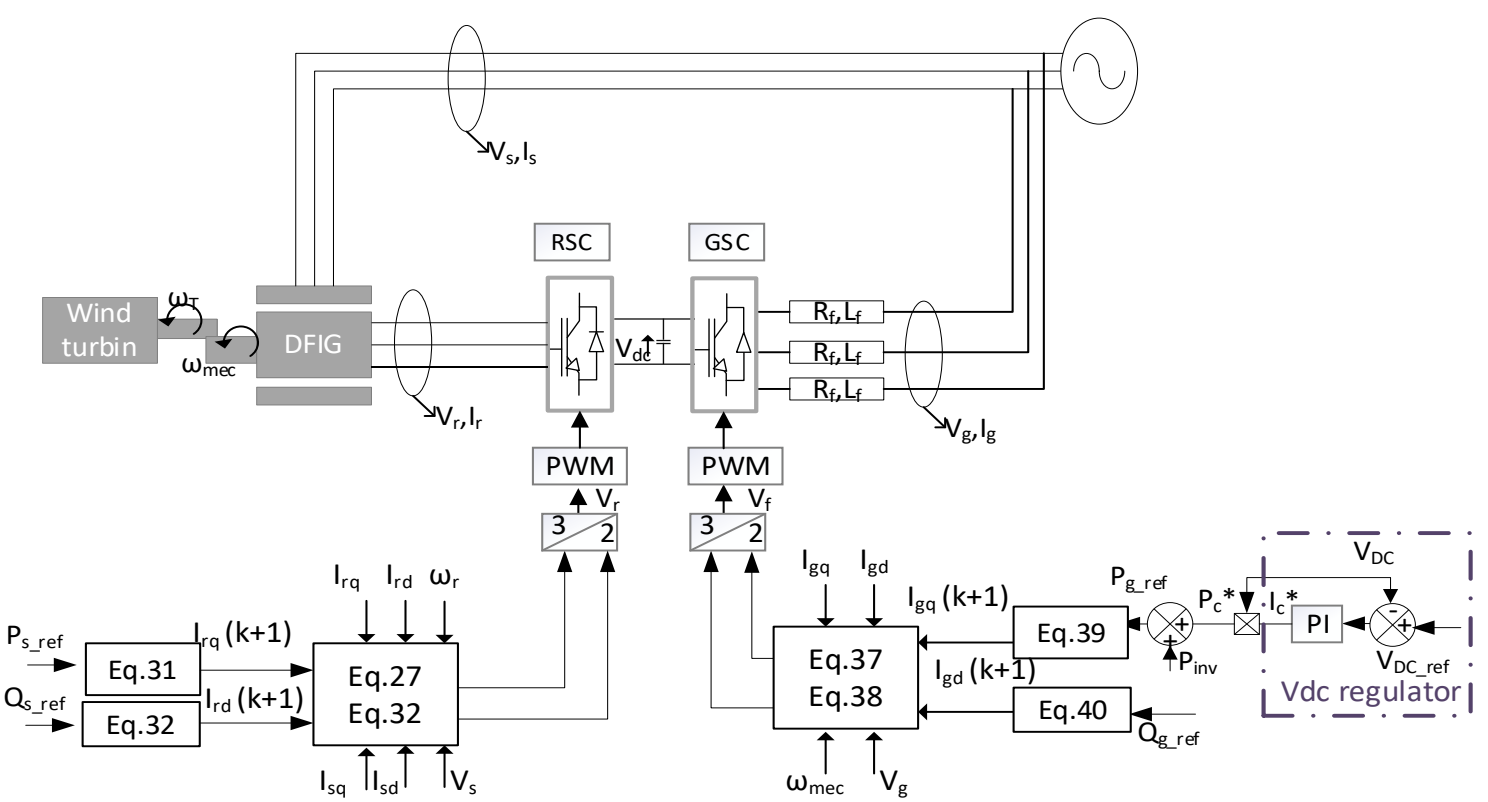

Figure 1. Deadbeat control applied to WECS

\section{RESULTS AND DISCUSSION}

In order to test and validate the control developed previously, some tests have been performed. First of all, a random wind profile with a zero reactive power setpoint is applied to the system. Figure 2 shows the wind profile used, which has an average value of $8 \mathrm{~m} / \mathrm{s}$, while Figure 3 shows the electromagnetic torque that varies inversely with the wind profile. Figure 4 and Figure 5 show the active and reactive stator powers.

It is clear that the decoupling of these two powers is assured. The wind profile has the same inverse form as the active power, which follows its reference with a $20 \mathrm{~W}$ error and a response time of $0.6 \mathrm{~s}$. The fact that the equipment is in generator mode explains the negative figure of active power. The reactive power follows its reference with a response time of $0.4 \mathrm{~s}$ and a deviation of (5Var). Figure 6 illustrates the quadrature rotor current. It is shaped like the inverse of active power as shown in Figure 2. Ps changes linearly with Irq through the negative coefficient indicated in (31) therefore this result was expected. Figure 7 illustrates the direct rotor current. Since Qref is set to zero and the remaining constant ratio s/Lm (32) is equal to $5 \mathrm{~A}$, it has a constant value of about $5 \mathrm{~A}$. Rotor quadrature and direct current errors were found to be fewer than $0.025 \mathrm{~A}$. This little error proves that they effectively reached their references.

As the current is the power picture, Figure 8 depicts stator currents with an inverse form matching to the wind profile. While the profile fluctuates, the currents maintain a sinusoidal form with a period of $0.02 \mathrm{~s}$, 
providing a frequency equal to the grid frequency of $50 \mathrm{hz}$. The normalized value of THD must be less than $5 \%$ to have acceptable quality power. In this investigation, the THD was less than $0.27 \%$ as shown in Figure 9 , indicating good power quality. Figure 10 depicts the rotor current profile, which fluctuates sinusoidally and proportionately with the electromagnetic torque. From $t=6 \mathrm{~s}$ to $\mathrm{t}=8 \mathrm{~s}$, the current form transitions: the generator switches from subsynchronism to hypersynchronism mode. Concerning VDC response, it can be seen in Figure 11 that Dc link voltages need 0.18s to reach the constant reference value of $600 \mathrm{~V}$. An overshoot of $8.3 \%$ explains the VDC peak.

On the other hand, the grid active and reactive powers are illustrated in Figure 12 and Figure 13, respectively. The Pg has the same shape as the Ps profile, and Qg profile has the same shape as the Qs profile. As for the Ig, Figure 14 shows that the currents grid has the same sinusoidal shape and the same period as Is. These results testified in the interest of controlling RSC and GSC simultaneously tracking the shape of the wind to inject the produced electricity into the grid. As shown in Figure 15, the voltage and current of one phase of the grid are sinusoidal with the same period of $0.02 \mathrm{~s}$ in phase opposition, ensuring the unit power factor.

To test and verify the control's robustness and performance, the ability of Ps to track the reference needs to be checked. A step has been applied as a reference, while stator and rotor resistances have been changed from Resistance/2 to Resistance*2. As shown in Figures 16 and Figure 17 can be seen that the tracking is still ensured despite the slight increase of the oscillations. A comparison of results between the developed control and other recent studies is shown in the Table 1. It should be mentioned that they do not refer to the same conditions since it is very difficult to find several works done under the same conditions. Although the response time is slightly higher than the response time proposed by [8], the biggest advantage of the deadbeat control is the significant reduction of the tracking error, and the error was reduced by $65 \%$ compared to the BSC and 87\% compared to the FOC. Comparing the THD of this study with [31] and [12], it is remarkable that the THD has been reduced in a very significant way for the four types of controls proposed. All this leads, the Deadbeat controller proposes the best produced energy in terms of performance, robustness and quality.

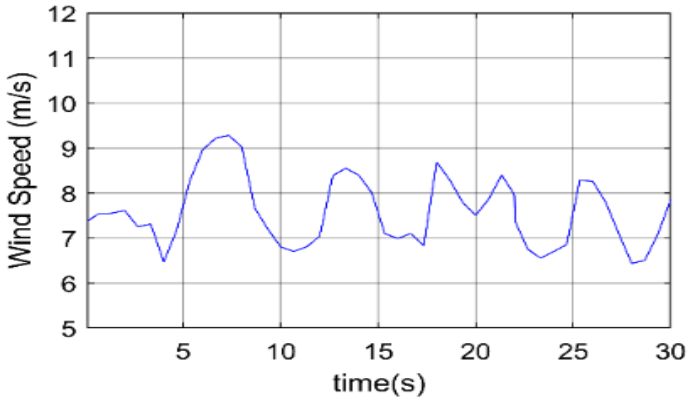

Figure 2. Wind speed $(\mathrm{m} / \mathrm{s})$

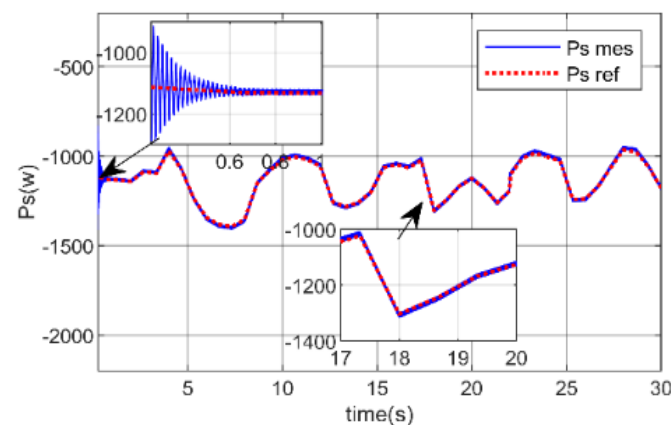

Figure 4. Stator active power (W)

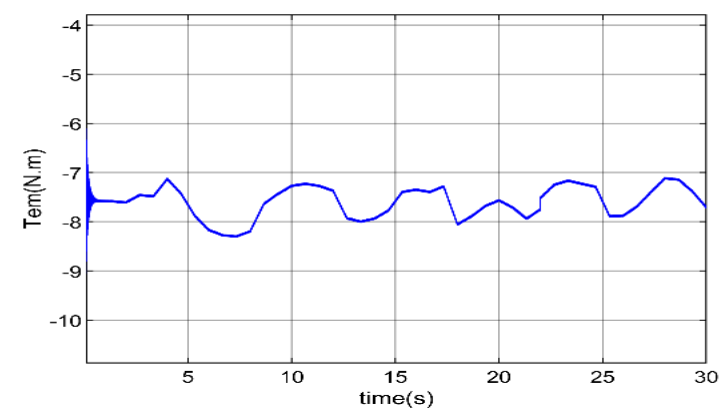

Figure 3. Electromagnetic torque (N.m)

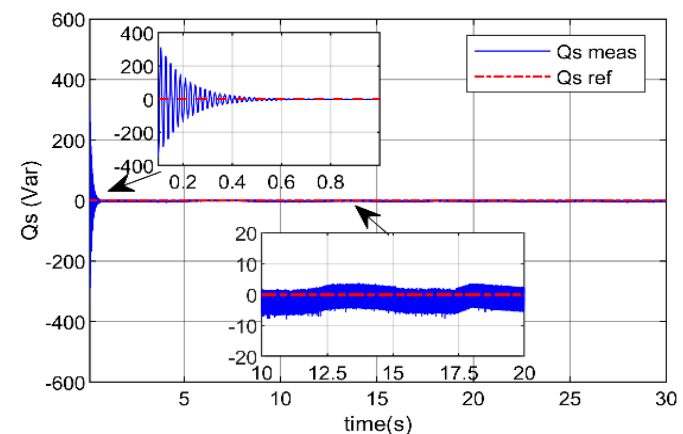

Figure 5. Stator reactive power (Var) 


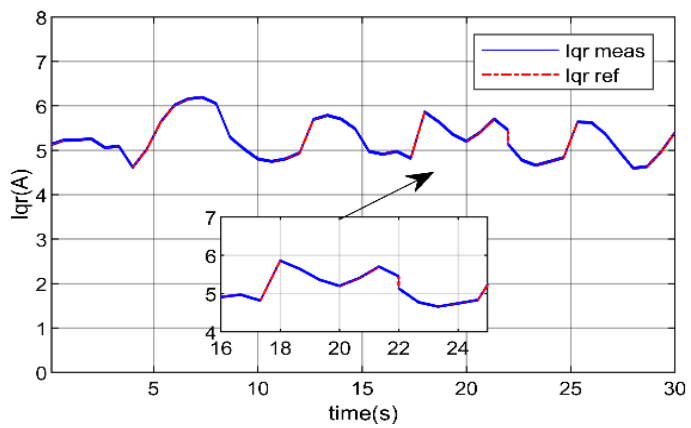

Figure 6. Rotor quadrature current (A)

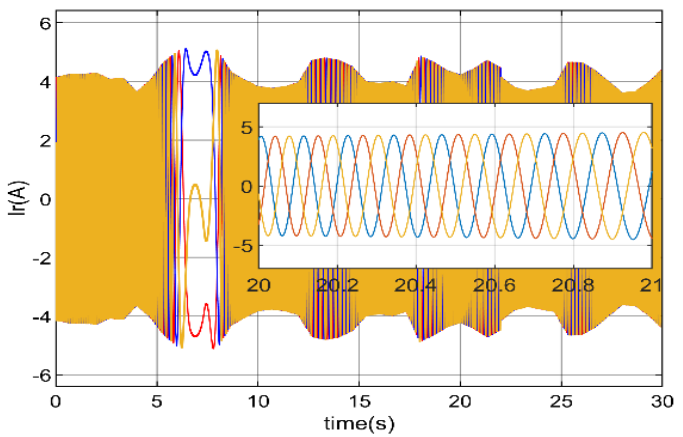

Figure 8. Stator currents (A)

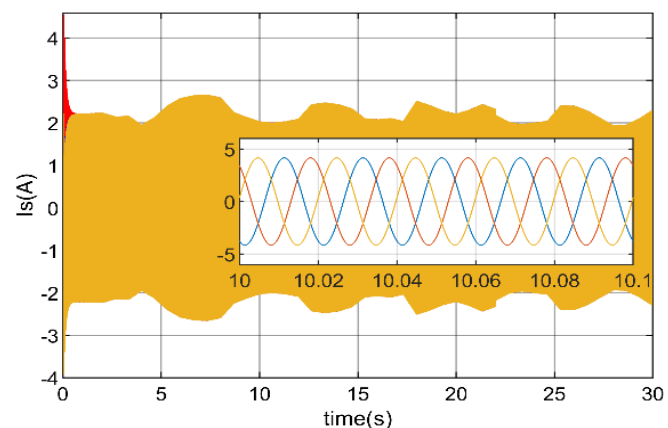

Figure 10. Rotor currents (A)

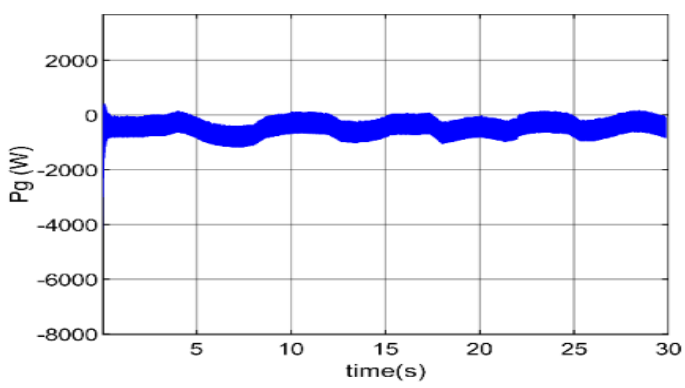

Figure 12. Grid active power (W)

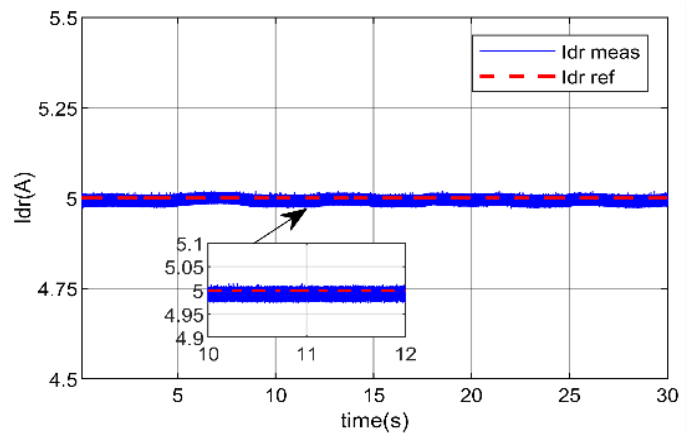

Figure 7. Rotor direct current (A)

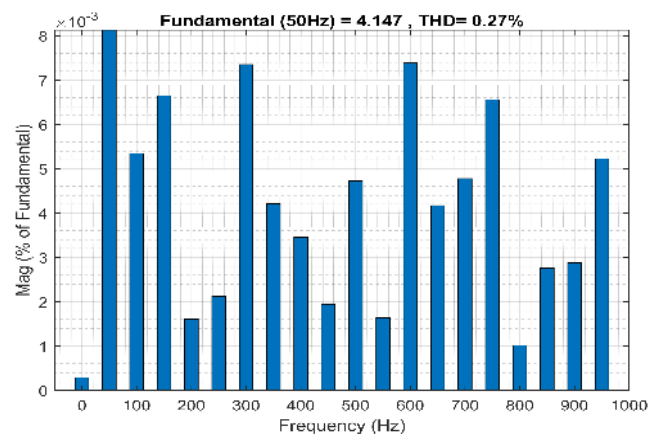

Figure 9. Stator currents THD

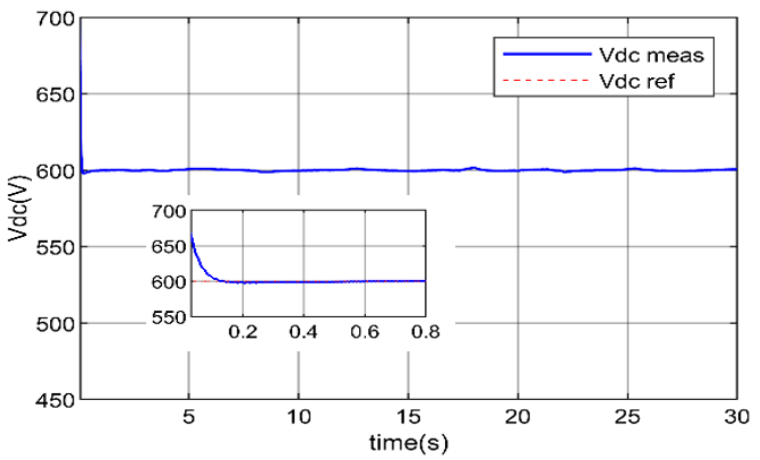

Figure 11. Dc link voltage (V)

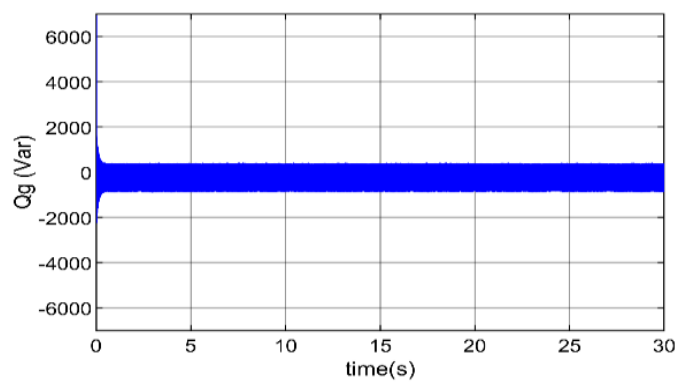

Figure 13. Grid reactive power (Var) 


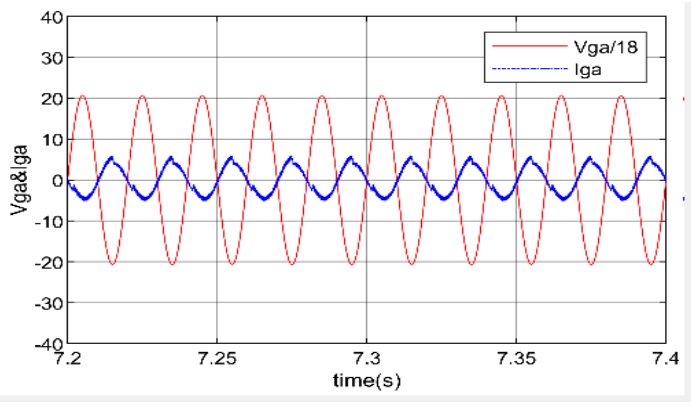

Figure 14. Grid voltage \& current phase a

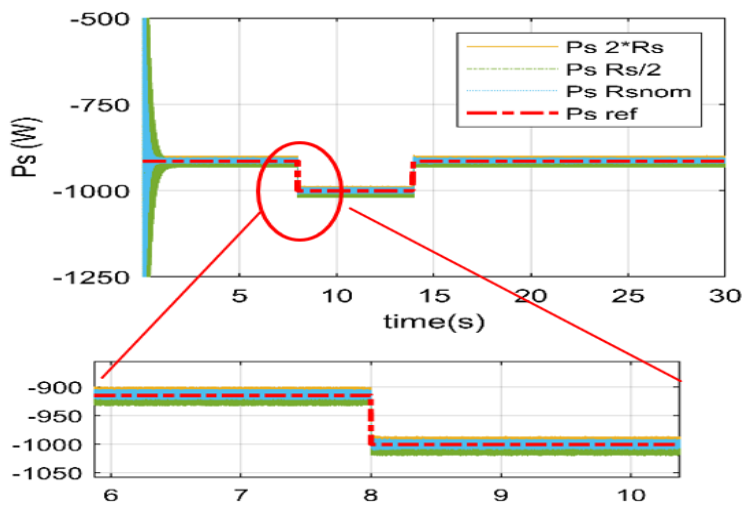

Figure 16. Stator active power by varying Rs

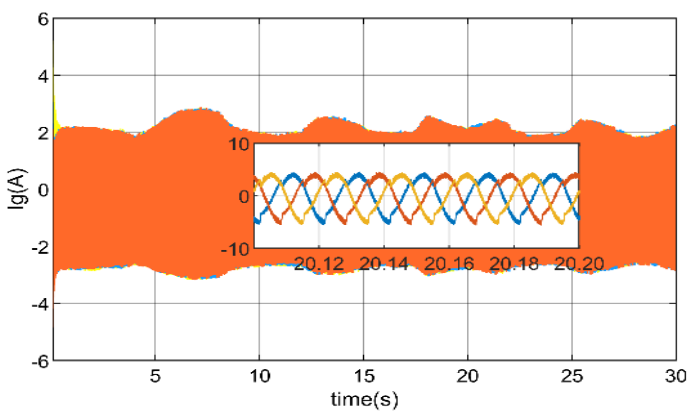

Figure 15. Grid current (A)

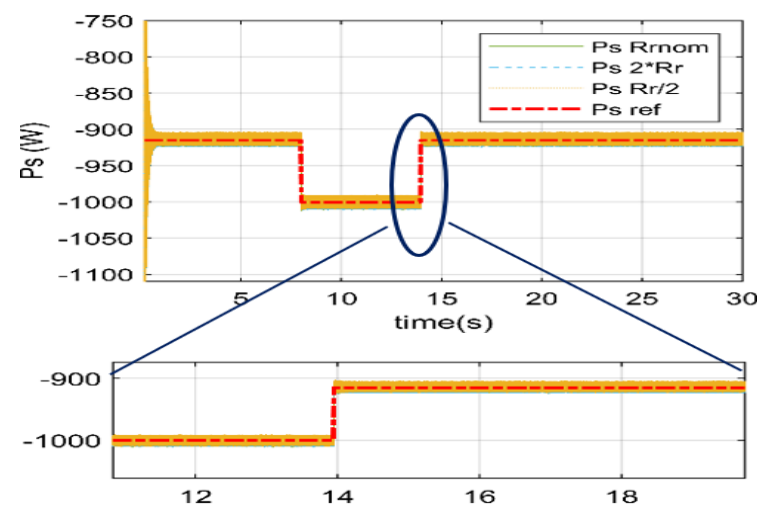

Figure 17. Stator active power by varying $\mathrm{Rr}$

Table 1. Performance's comparison

\begin{tabular}{ccccc}
\hline Ref & Control method & Response time (s) & Error (\%) & THD (\%) \\
\hline$[8]$ & Backstepping & 0.3 & 1.17 & - \\
& Vector control & 0.8 & 3.3184 & - \\
{$[31]$} & Direct Power Control & - & -- & 5.17 \\
& Vector control & - & - & 5.95 \\
{$[12]$} & Backstepping & - & - & 2.36 \\
& Sliding mode & - & - & 3.99 \\
{$[14]$} & Sliding mode & - & - & 2.98 \\
& Deadbeat controller & 0.4 & 0.4 & 0.27 \\
\hline
\end{tabular}

\section{CONCLUSION}

The predictive power regulation of a doubly-fed induction generator was examined. The deadbeat command was designed to control the powers systems through the currents. The deadbeat control recommended the appropriate voltages to the back-to-back converter at each sample period based on discretetime to achieve the required set-points, control the powers and the DC link voltages. To guarantee decoupling between the two components, axes d, and q, field-oriented control was used. For these goals, the system was provided initially, followed by a discussion of the deadbeat predictive control approach, and finally, applying this strategy to rotor and grid side control. With a unitary power factor, a random wind profile was utilized to examine the system's performance. Using a $1.5 \mathrm{~kW}$ Doubly Fed Induction Generator, the simulation results are shown in the MATLAB/Simulink environment.

With the use of a random wind profile, the results produced have met the control and system objectives by assuring good reference tracking; they have also met the normalization standards, yielding a THD of $0.27 \%$ and a frequency of 50 hertz. The excellent tracking that allows the machine's internal characteristics to vary attests to the control's durability. The deadbeat controller was found to be quite promising as compared to other control systems in terms of quality and tracking reference. Once these results in the MATLAB software are produced, as a perspective, the application of these commands on the test bench is conceivable. 


\section{REFERENCES}

[1] C. Emeksiz and B. Demirci, "The determination of offshore wind energy potential of Turkey by using novelty hybrid site selection method," Sustain. Energy Technol. Assessments, vol. 36, no. 100562, 2019, doi: 10.1016/j.seta.2019.100562.

[2] B. Iea, "Morocco 2019," 2019. https://www.iea.org/reports/energy-policies-beyond-iea-countries-morocco-2019.

[3] S. Sumathi, L. Ashok Kumar, and P. Surekha, "Solar PV and Wind Energy Conversion Systems," Springer Link, 2015.

[4] S. Karad and R. Thakur, "Recent Trends of Control Strategies for Doubly Fed Induction Generator Based Wind Turbine Systems: A Comparative Review," Archives of Computational Methods in Engineering, vol. 28, no. 1, pp. 15-29, 2021, doi: 10.1007/s11831-019-09367-3.

[5] S. Boubzizi, H. Abid, A. El hajjaji, and M. Chaabane, "Comparative study of three types of controllers for DFIG in wind energy conversion system," Protection and Control of Modern Power Systems, vol. 3, no. 1, pp. 1-12, 2018, doi: 10.1186/s41601-0180096-y.

[6] M. Bouderbala et al., "Modeling and Power Controls of Wind Energy Conversion Systems Based on Doubly Fed Induction Generator," 6th International Renewable and Sustainable Energy Conference (IRSEC), 2018, pp. 1-6, doi: 10.1109/IRSEC.2018.8702959.

[7] M. Elmahfoud, B. Bossoufi, M. Taoussi, N. El Ouanjli, and A. Derouich, "Comparative study between backstepping adaptive and field oriented controls for doubly fed induction motor," European Journal of Electrical Engineering, vol. 22, no. 3, pp. 209-221, 2020, doi: 10.18280/ejee.220302.

[8] M. Taoussi, M. Karim, D. Hammoumi, C. E. Bekkali, B. Bossoufi and N. E. Ouanjli, "Comparative study between backstepping adaptive and field-oriented control of the DFIG applied to wind turbines," International Conference on Advanced Technologies for Signal and Image Processing (ATSIP), 2017, pp. 1-6, doi: 10.1109/ATSIP.2017.8075592.

[9] B. Bossoufi et al., "Rooted Tree Optimization for the Backstepping Power Control of a Doubly Fed Induction Generator Wind Turbine: dSPACE Implementation," IEEE Access, vol. 9, pp. 26512-26522, 2021, doi: 10.1109/ACCESS.2021.3057123.

[10] H. A. Aroussi, E. M. Ziani, M. Bouderbala, and B. Bossoufi, "Enhancement of the direct power control applied to DFIG-WECS," International Journal of Electrical and Computer Engineering IJECE, vol. 10, no. 1, pp. 35-46, 2020, doi: 10.11591/ijece.v10i1.pp35-46.

[11] A. Kadri, H. Marzougui, and F. Bacha, "Implementation of direct power control based on stator flux estimation using low-pass filter estimator for doubly fed induction generator-wind energy conversion system," Proceedings of the Institution of Mechanical Engineers, Part I: Journal of Systems and Control Engineering, vol. 233, no. 7, pp. 764-778, 2019, doi: $10.1177 / 0959651818818895$.

[12] Y. Ihedrane, C. El Bekkali, M. El Ghamrasni, S. Mensou, and B. Bossoufi, "Improved wind system using non-linear power control," Indonesian Journal of Electrical Engineering and Computer Science, vol. 14, no. 3, pp. 1148-1158, 2019, doi: 10.11591/ijeecs.v14.i3.pp1148-1158.

[13] B. Sarsembayev, K. Suleimenov, B. Mirzagalikova and T. D. Do, "SDRE-Based Integral Sliding Mode Control for Wind Energy Conversion Systems," IEEE Access, vol. 8, pp. 51100-51113, 2020, doi: 10.1109/ACCESS.2020.2980239.

[14] H. Lhachimi, Y. Sayouti, and Y. El Kouari, "Optimal improvement of direct power control strategy based on sliding mode controllers," Computers \& Electrical Engineering, vol. 71, pp. 637-656, 2018, doi: 10.1016/j.compeleceng.2018.08.013.

[15] J. Hu, K. Wai, and E. Cheng, "Predictive Control of Power Electronics Converters in Renewable Energy Systems," energies, vol. 10, no. 4, pp. 1-14, 2017, doi: 10.3390/en10040515.

[16] K. N. W Liuping, S. Chai, D. Yoo, L. Gan, "PID and Predictive Control of Electrical Drives and Power Converters using Matlab/Simulink," Wiley-IEEE Press, 2015.

[17] A. J. S. Filho and E. Ruppert, "Experimental results of deadbeat power control implementation for DFIG," 10th International Conference on Environment and Electrical Engineering, 2011, pp. 1-4, doi: 10.1109/EEEIC.2011.5874670.

[18] H. G. Khesht and M. Monfared, "Deadbeat direct power control for grid connected inverters using a full-order observer," 4th International Conference on Electric Power and Energy Conversion Systems (EPECS), 2015, pp. 1-5, doi: 10.1109/EPECS.2015.7368540.

[19] T. Ackermann, Wind Power in Power Systems Edited," John Wiley and Sons, 2012.

[20] H. A. Aroussi, E. Ziani, M. Bouderbala and B. Bossoufi, "DPC \& DNPC Applied To Wind Energy Converter System," 5th International Conference on Renewable Energies for Developing Countries (REDEC), 2020, pp. 1-6, doi: 10.1109/REDEC49234.2020.9163898.

[21] G. Abad, J. López, M. A. Rodríguez, L. Marroyo, and G. Iwanski, "Doubly Fed Induction Machine: Modeling and Control for Wind Energy Generation," John Wiley and Sons, 2011.

[22] T. S. L. V. Ayyarao, "Modified vector controlled DFIG wind energy system based on barrier function adaptive sliding mode control," Protection and Control of Modern Power Systems, vol. 4, no. 1, pp. 1-8, 2019, doi: 10.1186/s41601-019-0119-3.

[23] M. Rahimi, "Coordinated control of rotor and grid sides converters in DFIG based wind turbines for providing optimal reactive power support and voltage regulation," Sustainable Energy Technologies and Assessments, vol. 20, pp. 47-57, 2017, doi: 10.1016/j.seta.2017.02.012.

[24] V. Q. Binh, N. Algorithmes, and D. De, "Algorithmes de conception de lois de commande prédictives pour les systèmes de production d 'énergie," Université Paris-Saclay Préparée à CentraleSupélec Communication, 2017.

[25] I. Rkik, M. El khayat, H. Hamidane, A. Ed-Dahhak, M. Guerbaoui, and A. Lachhab, "An intelligent lead-acid battery closed-loop charger using a combined fuzzy controller for PV applications,” E3S Web of Conferences, vol. 297, no. 01033, pp. 1-8, 2021, doi: $10.1051 /$ e3sconf/202129701033.

[26] C. Edwards, T. Lombaerts and M. H. Smaili, "Lecture Notes in Control and Information Sciences: Preface," vol.399, 2010.

[27] M. Bouderbala et al., "Experimental Validation of Predictive Current Control for DFIG : FPGA Implementation," electronics, vol. 10, no. 21, pp. 1-15, 2021, doi: 10.3390/electronics10212670.

[28] Z. Zhang, Z. Cui, Z. Zhang, R. Kennel and J. Rodríguez, “Advanced Control Strategies for Back-to-Back Power Converter PMSG Wind Turbine Systems," IEEE International Symposium on Predictive Control of Electrical Drives and Power Electronics (PRECEDE), 2019, pp. 1-6, doi: 10.1109/PRECEDE.2019.8753366.

[29] B. Manale, B. Badre, A. A. Hala, T. Mohammed, L. Ahmed and L. Petru, "DEADBEAT Control Applied toWind Power System," 5th International Conference on Renewable Energies for Developing Countries (REDEC), 2020, pp. 1-5, doi: 10.1109/REDEC49234.2020.9163601.

[30] M. E. Achkar, R. Mbayed, G. Salloum, N. Patin and E. Monmasson, "Voltage Control of a Stand-Alone Cascaded Doubly Fed Induction Generator," IEEE Transactions on Industrial Electronics, vol. 66, no. 1, pp. 762-771, 2019, doi: 10.1109/TIE.2018.2856186. 
[31] Y. Djeriri, A. Meroufel, A. Massoum, and Z. Boudjema, “A comparative study between field oriented control strategy and direct power control strategy for DFIG,” Journal of Electrical Engineering, vol. 14, no. 2, pp. 159-167, 2014.

\section{BIOGRAPHIES OF AUTHORS}
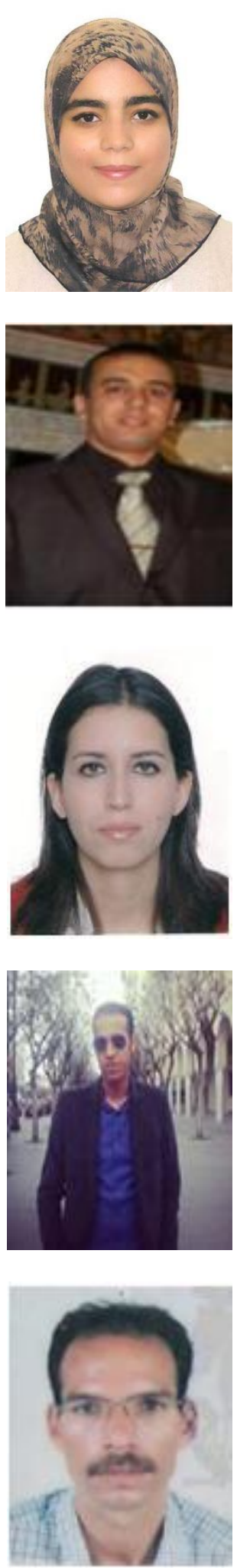

Manale Bouderbala (iD SC $\mathrm{P}$ is a Ph.D. Student in Electrical Engineering from the Faculty of Sciences Dhar El Mahraz, Sidi Mohammed Ben Abdellah University, Fez, Morocco. She is member of LISTA Laboratory. She had her master's degree in Engineering of Industrial Automated Systems at the Faculty of Sciences Dhar el Mahrez Fez. Her research interests include Renewable Energy, static converters, electrical motor drives, and power electronics. She can be contacted at email: manale.bouderbala@usmba.ac.ma.

Badre Bossoufi (D) 8d SC P was born in Fez city, Morocco, on 1985. He received the Ph.D. degree in Electrical Engineering from University Sidi Mohammed Ben Abdellah, Faculty of Sciences, Morocco and PhD. degree from University of Pitesti, Faculty of Electronics and Computer, Romanie and Montefiore Institute of electrical engineering, Luik, Belgium, in 2012. He was a Professor of Electrical Engineering, at the Faculty of Sciences, Sidi Mohamed Ben Abdellah University, Fez, Morocco. His research interests include static converters, electrical motor drives, and power electronics, Smart Grid, Renewable Energy and Artificial Intelligent He can be contacted at email: Badre_isai@hotmail.com.

Hala Alami Aroussi (D) 8d SC P received her M.S degree in Industrial Automated Systems Engineering from Sidi Mohammed Ben Abdellah University, Fez, Morocco. She is currently pursuing her Ph.D in Electrical Engineering - Renewable Energy at Mohamed Premier University, Oujda, Morocco. She is a member of the laboratory of electrical engineering and maintenance (LGEM). Her research interests include modeling, control of wind energy conversion systems applied to a doubly fed induction machine using DSPACE. She can be contacted at email: h.alamiarroussi@ump.ac.ma.

Mohammed Taoussi (DD SC P was born in Fez city, Morocco. Professor of University Sidi Mohammed Ben Abdellah.. Ph.D. Student in Electrical Engineering from University Sidi Mohammed Ben Abdellah, Faculty of Sciences, Morocco. He received the MASTER degree in industrial electronics from the Faculty of Sciences- Fez, in 2013. His research interests include static converters, electrical motor drives, and power power electronics, Smart Grid, Renewable Energy and Artificial Intelligence. He can be contacted at email: m.taoussi0@gmail.com.

Ahmed Lagrioui (D) S SC P is a professor in ENSAM-Mekness, University Mly Smail, Morocco. He re- ceived the Ph.D. degree in Electrical Engineering from the Mohammadia school's of engineers, Rabat, Morocco. He received the aggregation degree in electrical engineering from the ENSET School, in 2003. He received the DESA degree in industrial electronics from the Mohammadia school's of engineers. His research interests include static converters, electrical motor drives and power electronics. He can be contacted at email: a.lagrioui71@gmail.com. 